
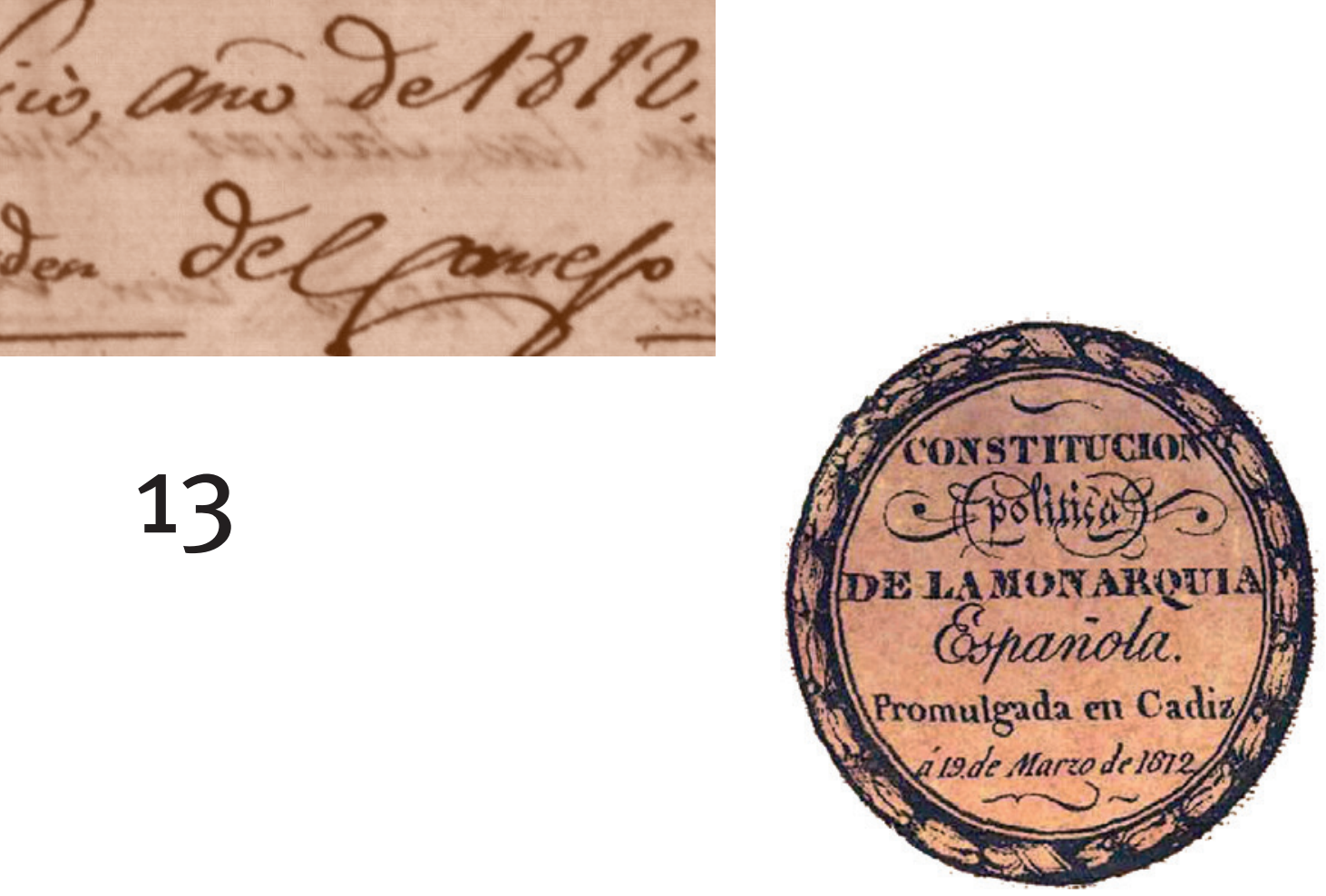

13

romulgada en Cadiz
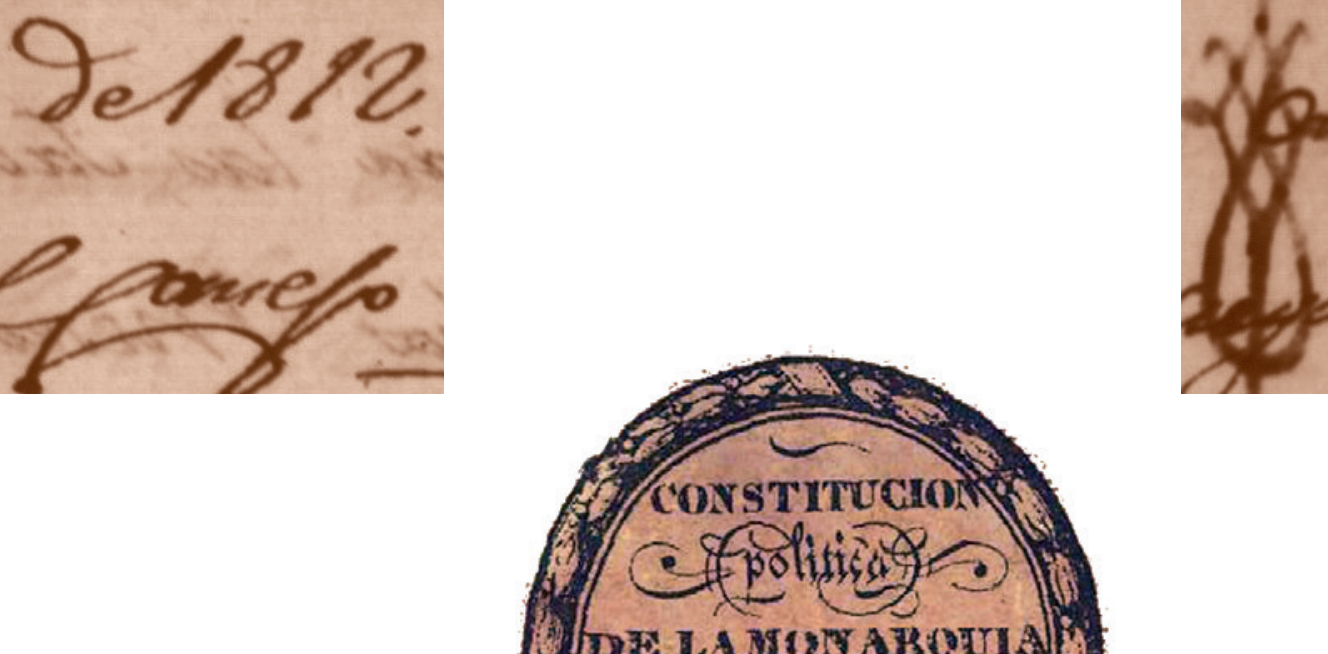



\section{Colección $\mathbf{I m u d}$ \\ n. ${ }^{\text {13 }}$}

\section{LA PROVINCIA DE LA MANCHA Y LA CONSTITUCIÓN DE 1812}





\section{Carlos Chaparro Contreras \\ e Isidro Sánchez Sánchez (eds.)}

\section{LA PROVINCIA DE LA MANCHA Y LA \\ CONSTITUCIÓN DE 1812}

Ediciones de la Universidad

de Castilla-La Mancha

Cuenca, 2021 
LA PROVINCIA de La Mancha y la Constitución de 1812 / editores, Carlos Chaparro Contreras, Isidro Sánchez Sánchez.- Cuenca : Ediciones de la Universidad de Castilla-La Mancha, 2020

341 p. ; 24 cm.- (Almud ; 13)

ISBN 978-84-9044-311-8

1. España - Constitución - 1812 2. Castilla-La Mancha - Historia I. Chaparro Contreras, Carlos, ed. lit. II. Sánchez Sánchez Isidro, ed. lit. III. Universidad de Castilla-La Mancha, ed. IV. Serie

342.4(460)"1812"

946.028

1DSE-ES-G

NHD

(C) de los textos e imágenes: sus autores.

(C) de la edición: Universidad de Castilla-La Mancha.

Edita: Ediciones de la Universidad de Castilla-La Mancha y Centro de Estudios de Castilla-La Mancha.

Colección Almud n. ${ }^{\circ} 13$.

Diseño de la colección:

C.I.D.I. (Universidad de Castilla-La Mancha).

unte Unión de Edtorlales
Universitarias Españolas nacional.

Esta editorial es miembro de la UNE, lo que garantiza la difusión y comercialización de sus publicaciones a nivel nacional e inter-

ISSN: $1988-0979$

I.S.B.N.: 978-84-9044-311-8 (Edición impresa)

I.S.B.N.: 978-84-9044-434-4 (Edición electrónica)

D.O.I.: http://doi.org/10.18239/alm_2021.13.00

D.L.: CU 248-2019

Composición: Compobell S.L.

Impresión: Gráficas Izquierdo

Hecho en España (U.E.) - Made in Spain (U.E.)

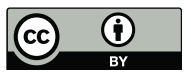

Esta obra se encuentra bajo una licencia internacional Creative Commons CC BY 4.0.

Cualquier forma de reproducción, distribución, comunicación pública o transformación de esta obra no incluida en la licencia Cretative Commons CC BY 4.0 solo puede ser realizada con la autorización expresa de los titulares, salvo excepción prevista por la ley. Puede Ud. acceder al texto completo de la licencia en este enlace: https://creativecommons.org/licenses/by/4.0/deed.es 


\section{ÍNDICE}

Presentación ..................................................................................

Gabino Marco Solera, Carmen María Montalbán Martínez y Antonio Ruiz Lucas

Las Cortes y la Constitución de Cádiz: contenidos sociales y esperanzas populares

Juan Sisinio Pérez Garzón

La Constitución de 1812

Enrique Belda Pérez-Pedrero

Guerra y revolución en La Mancha Ángel Ramón del Valle Calzado

El Partido de Alcaraz a finales del Antiguo Régimen

65 Carmen Hernández López y Francisco García González

"Napoleón emperador" y el destino del Partido de Almagro......... José Gregorio Cayuela Fernández

La Mancha, 1812: El partido judicial de Villanueva de los Infantes Lucía Crespo Jiménez

Representación y educación político-popular en las ceremonias y fiestas de proclamación y jura de la Constitución de 1812 en La Mancha

Carlos Chaparro Contreras

La crisis del Antiguo Régimen en La Mancha (1787-1808). El caso de Villanueva de los Infantes y su partido.... Carlos Javier Rubio Martínez 
Los manchegos que auparon a la "Pepa"

Enrique Jiménez Villalta

Almadén y la Constitución de Cádiz (1812-1814)

245

Julián Prior Cabanillas

El padre Agustín de Castro y la prensa periódica

273 Isidro Sánchez Sánchez 


\title{
LA CONSTITUCIÓN DE 1812
}

\author{
ENRIQUE BELDA PÉREZ-PEDRERO \\ Facultad de Derecho y Ciencias Sociales de Ciudad Real (UCLM)
}

Es un placer el hecho de poder dirigirme a ustedes desde este foro, en una tierra con la que tan unido me siento. Compartir cartel con compañeros investigadores del ámbito de la Historia es todo un honor que se presenta en contadas ocasiones como la presente, donde la Ciencia Jurídico-Constitucional entra en sana convivencia con la explicación histórica de una de las fuentes normativas de España, calificada como de las más extraordinarias y relevantes. Agradezco a los organizadores esta invitación y envío un saludo muy especial al Dr. Isidro Sánchez, que la ha concretado, y que siempre me tiene en cuenta.

Sería pretencioso o simplemente absurdo en el año del bicentenario de la Constitución gaditana y cuando ya se han celebrado más de una treintena de congresos, jornadas y foros al efecto (sólo en el ámbito jurídico), que darán lugar, cuando menos, a una docena de obras de referencia en la materia, intentar abordar en treinta minutos una presentación del tema, buscando de cualquier forma una completa aproximación. Como he tenido ocasión de participar desde 2009 en un proyecto de investigación al efecto (Proyecto de Investigación I+D "La Constitución de 1812 y su influencia en América: orígenes y desarrollo del constitucionalismo español y latinoamericano". PII 1/09-0066-3787. Investigador Principal: Francisco Javier Díaz Revorio. Junta de Comunidades de Castilla-La Mancha. Fecha de inicio: 1-1-2009. Finalización: 31-12-2012), cuyos resultados están a punto de publicarse (DIAZ REVORIO, Francisco Javier y VERA SANTOS, José Manuel, La Constitución de 1812 y su difusión en Iberoamérica, Tirant lo blanc, Valencia, 2012), es muy fácil poder ofrecerles a estas alturas las conclusiones obtenidas por un nutrido grupo de investigadores, cada cual especia- 
lizado en un aspecto jurídico de la Carta Gaditana, que nos hemos unido desde varias universidades situadas a ambos lados del Atlántico.

Por lo demás evitaré repetir lo que todos ustedes saben y el significado para España de esta Constitución, que puede leerse en cualquiera de las publicaciones pasadas y presentes, emanadas al socaire de este bicentenario. Voy únicamente a trasladarles las conclusiones que en la materia de mi especialidad me parecen más novedosas, o zanjan polémicas doctrinales que hasta este nuevo replanteamiento no se habían formulado tal y como se las presentamos este grupo de profesores.

\section{La CONSTITUCIÓN DE 1812: SÍMBOLO Y MITO}

La Constitución de 1812 es una primera experiencia del constitucionalismo moderno, una fuente legal que sitúa al ordenamiento jurídico español en una ruptura con la dinámica recopilatoria y que cumple, con creces, su papel de inspirar el comienzo de la lenta evolución de un derecho pensado para el pueblo y no para las estructuras de poder. A partir de ese texto se plantea la "novedad" que introduce tímidamente las bases de un sistema liberal de derecho al tipo decimonónico, con la idea de continuar la estela revolucionaria francesa y norteamericana de finales del siglo anterior.

1812 es Derecho para España. Para la nación española. Eso es mucho, más cuando se plantea por primera vez. Pero probablemente se haya magnificado su influencia práctica posterior, especialmente en las naciones latinoamericanas nacidas a partir de 1810, donde la preeminencia de guía la asume la primera constitución americana y la constitución francesa. Pero en el texto de Cádiz, aunque en posición secundaria, terminamos por encontrar las principales preocupaciones orgánicas y ciudadanas que serán objeto de debate durante los dos siglos posteriores, tanto de nuestra historia, como de los países hermanos de América.

Formalmente, la tendencia a elaborar un instrumento normativo supremo que lo abarque todo, sí que constituye una imprescindible referencia de modernidad. En el antecedente de la Carta napoleónica de Bayona de 1808 ya pudimos conocer esta intención. Ahora bien, la verdadera importancia como primera referencia de la constitución gaditana frente a la de Bayona, es precisamente la articulación de un magnifico proceso constituyente, de participación y pseudodemocratización (en un delicado momento histórico), que es lo que permite hablar de verdadera Constitución y no de mera "Carta Otorgada".

De la misma forma que el instrumento en sí, la forma "de Constitución”, es a mi modesto parecer el hecho más destacable, por importantes que sean las pautas de modernidad que ofrece el contenido; la forma y 
disposición temática dentro de ella, también nos alumbra el camino para las sucesivas Constituciones contemporáneas, e incluso para la vigente.

En cualquier caso, la novedad del contenido, sigue siendo una constante en todos los autores: "La originalidad de la Constitución de Cádiz reside en que no modificó el estado de las cosas sino que fue más allá: creó una nueva realidad"1.

\section{INFLUENCIAS}

“(...) el modelo del constitucionalismo español, lejos de ser una mera copia del francés de 1791, tiene perfiles propios y originales.”2. Así es. Nuestro texto no es una reproducción del vecino país y acoge en su estructura la tradición orgánica española, además de aspectos autóctonos. La Constitución de Cádiz es una obra con visión universal de los problemas de su tiempo ${ }^{3}$. Renuncia a las visiones localistas y pretende una estabilidad racional. Su fuerza de ideario llega a lugares tan dispares como Rusia o Brasil ${ }^{4}$. Lo curioso es que tal incidencia venga de un texto apenas aplicado en la práctica del país para el que estaba pensado.

Como en el mundo de Las Artes sucede con los que mueren jóvenes, la escasa vigencia de la Constitución de Cádiz, que era un producto potencialmente bueno y ante todo, novedoso, nacido en situación de excepcionalidad, guerra y revolución; produjo una mitificación.

\section{LA SOBERANÍA NACIONAL}

"Es evidente que el momento histórico está todavía lejano respecto de la asunción de mecanismos democráticos como el sufragio universal y que el derecho de participación política se mediatiza con las restricciones introducidas a la condición de ciudadano. Pero no podríamos entender el movimiento constitucional sin su capital enfoque hacia el Gobierno representativo mediante las fórmulas que permiten poner en

1 J. M. López Ulla, en F. J. Díaz Revorio y J. M. Vera Santos, La Constitución de 1812 y su difusión en Iberoamérica, Valencia, Tirant lo Blanc, 2012, p. 51.

2 F. J. Diaz Revorio, en F. J. Díaz Revorio y J. M. Vera Santos, La Constitución de 1812 y su difusión..., p. 18.

3 M. Chust, "La Constitución de 1812: una carta universal", en VV. AA., La Constitución de Cádiz y su buella en América, Cádiz, Universidad de Cádiz, 2011, p. 119 y ss.

4 E. González Hernández, en F. J. Díaz Revorio y J. M. Vera Santos, La Constitución de 1812 y su difusión..., p. 300. "La Constitución española de 1812 fue un texto conocido rápidamente en toda Europa, al poco de su promulgación, provocando una impresión considerable, pues, como ya hemos anticipado, la Constitución francesa de 1791 estaba casi olvidada”, siguiendo a B. Mirkine-Guetzevitch, "L'histoire constitutionnelle comparé", Annales de l'Institut de Droit Comparé de l'Université de París, vol. II, 1936, p. 89. Influencia en Rusia, p. 307 y en Brasil, p. 314. 
clave operativa el principio de la Soberanía Nacional. Desde esta perspectiva podemos afirmar que la Constitución de 1812 es, sin duda, uno de los textos primigenios que consagra mayor extensión a la implantación del Gobierno representativo." ${ }^{5}$. El proceso de formación de un Estado social y democrático de derecho como el alcanzado con la vigencia de la Constitución de 1978, demanda un germen inicial que luego da paso a un lento camino en todas las naciones de nuestro entorno. En el caso español esta evolución ha sido lenta, paralizada y recuperada hace cuatro décadas. Pero de haber continuado su natural evolución desde las constituciones del siglo XIX y sin la interrupción de la vigencia del texto constitucional de 1876 en el año 1923, también habría demandado una evolución pareja para consolidar esta idea, que posteriormente se perfecciona en términos de soberanía popular. La soberanía del pueblo, hoy, evita la imprecisión del término "nación”, así como su carga ideológica, valorativa y extrajurídica.

\section{LOS DERECHOS. Su TÍMIDA APARICIÓN}

La declaración de derechos es una novedad, pero estos se expresan parcialmente y sin intención de universalidad'. "En la Constitución de Cádiz no existe una Declaración de Derechos, sin duda para no dar pie a quienes estaban dispuestos a identificarla con la obra de las Constituyentes francesas, de modo que salvo una garantía general establecida en el art. 4 (...), los diversos preceptos relativos a los derechos se encuentran desparramados por el texto" 7 .

La Constitución de 1812 en este sentido, acoge algunos de los derechos civiles y políticos de primera generación. Habría que esperar al siglo Xx y más en concreto a la Constitución de 1931 para ver reflejos al máximo nivel normativo de buena parte de los derechos sociales y económicos. Y a la de 1978 para observar con total nitidez el compromiso eficaz de los poderes públicos, es decir la efectividad de los derechos de todo tipo. El derecho histórico y comparado, durante la primera mitad del siglo XIX, ofrece múltiples ejemplos de igual comportamiento constituyente en estos primeros pasos.

5 J. L. García Ruiz, en F. J. Díaz Revorio y J. M. Vera Santos, La Constitución de 1812 y su difusión..., p. 122.

6 I. Fernández Sarasola, "La Constitución española de 1812 y su proyección europea e iberoamericana", en Fundamentos, núm. 2 (Monográfico sobre "Modelos en la historia constitucional comparada”, Joaquín Varela Suances-Carpegna, dir.), 2000, p. 28 y ss.

7 M. Masso Garrote, en F. J. Díaz Revorio y J. M. Vera Santos, La Constitución de 1812 y su difusión..., p. 359. 


\section{La representación en el Parlamento}

"En lo que atañe a las funciones de las Cortes, éstas superaban el ámbito meramente legislativo, y abarcaban los más destacados cometidos estatales. Y ello porque, a pesar de ser cotitulares de la potestad legislativa, junto con el rey -artículos 15 y 131.1 de la Constitución-, en la práctica monopolizaban dicha potestad." ${ }^{8}$. La exaltación del poder legislativo, propia del primer constitucionalismo, a corto plazo constituyó el primer problema del nuevo régimen. El monarca puede ser consciente de todo el poder que atesora por el peso de la historia, pero si además el pueblo que teóricamente va a ser objeto de representación, es propenso a esa idea (en su lógica, mayoritaria e imperante, lo correcto es que la potestas acompañe a la auctoritas, que popularmente sólo se reconoce al Rey), la puesta en marcha de las ideas de estos ilustrados, es una tarea titánica o inviable. El poso, la referencia y el recuerdo en las clases dirigentes de este camino iniciado en Cádiz, es la mayor aportación de su Carta Magna, ante la ausencia de una trayectoria aplicativa de este parlamentarismo.

\section{El Rey y la funCión ejeCUtiva}

“(...) las repercusiones de la introducción del principio de soberanía nacional afectaron sobre todo a la posición del monarca, que de ser el centro y "dueño" del sistema pasó a ser un órgano constituido del mismo. En lo sucesivo el título del monarca no será de derecho divino sino por la "gracia de Dios y de la Constitución"; y el Discurso preliminar considerará al Rey como "Jefe del Gobierno y primer magistrado de la Nación”. Mientras en el Antiguo Régimen el Rey personifica al Estado, en la Constitución de 1812, el Rey es Jefe de Gobierno y primer magistrado de la Nación." 9 . De nuevo, la Constitución de Cádiz se nos presenta como ruptura con el pasado y primera experiencia de cambio. La lógica del poder efectivo sobre territorios y personas choca con la intención de avance.

Las estructuras políticas tienden a mantenerse y la dinámica de mando efectivo del Rey puede pasar en un momento del todo a la nada (lo sucedido con La Corona en la Carta Magna de 1978) sólo cuando se ha producido un proceso de racionalización y democratización aprehendido por población y clase dominante. Cuando ello no es así, la letra constitucional se presenta como referente inspirador. Nada más.

8 A. M ${ }^{a}$ Valero Heredia, en F. J. Díaz Revorio y J. M. Vera Santos, La Constitución de 1812 y su difusión..., p. 267.

9 M. Masso Garrote, en F. J. Díaz Revorio y J. M. Vera Santos, La Constitución de 1812 y su difusión..., p. 356. 


\section{HACIA UNA NUEVA JUSTICIA}

"En asuntos judiciales, el reconocimiento de los principios de separación de poderes, de la independencia judicial, de la exclusividad y unidad jurisdiccional..., apuntaban a una importante transformación respecto de la posición que había de ocupar la magistratura en el Estado a partir de ese momento. (...)" ${ }^{10}$, pero "La magistratura española no logra consolidarse, ni en esos momentos iniciales del primer constitucionalismo español, ni, posteriormente, durante todo el siglo XIX y buena parte del Xx, como un auténtico poder. La estructura del Estado no sufrió un cambio tan radical como el inicialmente pretendido, especialmente con relación a la separación, autonomía e independencia de la justicia." 11.

La Justicia resulta un ejemplo significativo de la problemática común a cualquier primera constitución de un Estado Moderno. La letra queda en pretensión, logrando la realidad décadas después o a través de nuevos textos constitucionales decisivos. Todo el siglo XIX y buena parte del XX ve la historia de una lucha por la consecución de la efectividad de las instituciones jurídicas que contiene. Es decir, de promover la verdadera normatividad, fuerza y eficacia. Sólo cuando las constituciones consiguen colocarse en la cúspide del ordenamiento jurídico, la legalidad contagia todo el sistema. Sin un primer aliento, representado por la constitución de Cádiz, que significa la ruptura y la apertura del camino de cambio, no se conciben las felices evoluciones que concluyen en la institución pretendida. Todas las naciones de nuestro entorno muestran un proceso similar hasta llegar a una Justicia no sólo independiente, sino comprometida con el Valor Justicia (en nuestra Constitución actual, art. 1.1) y con la Justicia como derecho fundamental a obtener la tutela judicial efectiva de jueces y tribunales (art. 24 de la Constitución de 1978).

\section{LA RELIGIÓN}

La constitucionalización de la Iglesia Católica habitualmente criticada como elemento distorsionador del espíritu liberal, probablemente reflejaba más que ningún otro tema la voluntad y opinión del pueblo español. Ahora bien, que las élites ilustradas no se impusieran en este terreno, marco la historia posterior de nuestro recorrido como organización política, casi tanto como las guerras dinásticas o posteriormente la

10 M. L. Martínez Alarcón, en F. J. Díaz Revorio y J. M. Vera Santos, La Constitución de 1812 y su difusión..., p. 241.

11 M. L. Martínez Alarcón, en F. J. Díaz Revorio y J. M. Vera Santos, La Constitución de 1812 y su difusión..., p. 242. 
lucha de clases. "La confesionalidad del Estado asumida por las cortes de Cádiz y la prohibición constitucional de cualquier otra práctica religiosa marcará el futuro de nuestro Estado liberal en este terreno. (...) esta intolerancia religiosa, de difícil conexión con el espíritu liberal de la mayor parte de los preceptos de la Constitución de 1812, es tal y como hemos visto el tributo que hubo de pagarse por llegar a un consenso en el oratorio de San Felipe Neri" ${ }^{12}$. Se reflejó la realidad pero se alimentó la intolerancia, que no fue exclusiva del mundo religioso, durante los dos siglos siguientes.

\section{LOS REPRESENTANTES/CONSTITUYENTES}

La Constitución de 1812 sacada de su contexto histórico y de realidad social de la época, podría ser severamente criticada: “(...) había una supremacía del clero sobre otras profesiones con un total de noventa diputados eclesiásticos de los que seis son Obispos como los de Calahorra, Mallorca, Ibiza, Plasencia y Sigüenza En total los eclesiásticos representaban el 30\% de los diputados, seguidos por los abogados, un $18 \%$, que hacían un total de cincuenta y seis de los que veintidós pertenecían a la carrera Fiscal, treinta al Ejército y nueve a la Marina. La nobleza sólo tuvo catorce representantes, y los catedráticos fueron quince. El número de representantes de carrera libre se completa con un arquitecto, un bachiller y dos escritores. A ello hay que añadir ocho comerciantes de Cádiz, Cataluña y América, veinte diputados sin profesión, y cuarenta y nueve diputados pertenecientes a altos cargos del Antiguo Régimen"13.

Grave error sería tal crítica: los patriotas que desarrollan sus trabajos en el período constituyente representan el ideal de una sociedad en guerra y de imposible estructuración a efectos de generar una cadena representativa de base electoral racional. Sin embargo, esa mancha de origen es una constante preocupación para todos ellos, que en los trabajos parlamentarios acuden reiteradamente a la necesidad de estructurar un tipo de representación válido en la España que se pretende constituir. En este sentido han de leerse los artículos 27 a 103 de la Constitución de Cádiz. En efecto, la mayor constitucionalización del régimen electoral conocida en nuestra historia: 70 preceptos.

12 M. E. Rebato Peño, en F. J. Díaz Revorio y J. M. Vera Santos, La Constitución de 1812 y su difusión..., p. 210.

13 J. López de Lerma Galán, en F. J. Díaz Revorio y J. M. Vera Santos, La Constitución de 1812 y su difusión..., p. 155. 


\section{La PeRmanencia de la Constitución de CÁdiz de 1812 en la CONSTITUCIÓN ESPAÑOLA DE 1978}

Como puede comprobarse, lo que estamos celebrando es una referencia simbólica. El antecedente lejano que marca una nueva época, más que la idoneidad de un instrumento social con postulados vigentes.

La universidad y las letras españolas han mirado siempre con gran atención el proceso revolucionario que se deriva de la España invadida por Napoleón. Es una muestra de la grandeza que puede existir detrás de los pueblos que están dispuestos a cambiar, y de las élites que se proponen encauzar esas transformaciones: de una parte, se lucha contra el invasor pero de otra, se intenta convertir una nación a las ideas que (de una manera u otra) alumbraron la causa de quien te agrede.

La historia de la consolidación de los Estados contemporáneos está plagada de particularidades locales que impiden las generalizaciones con las que muchas veces nos han contado sus procesos configuradores, especialmente los revolucionarios. Pero no cabe duda que desde mediados del siglo XVIII hasta 1939, los países europeos, más tarde o más temprano, han protagonizado un episodio de rebeldía liberal impulsora de derechos, al tiempo que afrontaban guerras o convulsiones. A España le tocó pronto, y puede que por ello la ideología o sustrato filosófico de la transformación jurídica e institucional que alumbra nuestro primer constitucionalismo, no fuera capaz de arraigar, sucumbiendo ante la reacción de ideas más tradicionales. En cualquier caso, el proceso de elaboración de la Constitución de Cádiz, y ese mismo texto, son el punto de partida para nuestro Estado liberal de derecho, antecedente del entramado constitucional plenamente social y democrático, que venimos disfrutando desde 1978 .

Sobre la canalización de influencias renovadoras en ese período, muchas han sido las obras que la doctrina española nos ha ofrecido. Yo destacaría la de José María Portillo Valdés ${ }^{14}$. Y en este punto, no puede olvidarse nunca cómo España, receptora ideológica, también es co-exportadora de pensamiento dentro de su ámbito, de una forma muy rápida, e incluso a su pesar. Como sintetiza Domingo García Belaunde ${ }^{15}$, toda la trayectoria histórica de la independencia latinoamericana se agrupa entre 1808, con la invasión francesa de España, y 1824, año de la batalla de Ayacucho. Los territorios que escapan a la secesión en esos quince años será ya porque obtienen su independencia al desgajarse a su vez de otros

14 Revolución de nación: orígenes de la cultura constitucional en España, 1780-1812. CEPCBOE, Madrid, 2000.

15 "El constitucionalismo latinoamericano y sus influencias", en Textos Constitucionales Históricos. El constitucionalismo Europeo y Americano en sus documentos. F. J. Díaz Revorio (comp.), Palestra, págs, 37 a 50, Lima, 2004, p. 38. 
nuevos Estados (por ejemplo, Ecuador de la Gran Colombia, en 1830, o Panamá, también de Colombia, en 1903), y con la excepción de Cuba y Puerto Rico, que se independizan de España a raíz de la guerra con Estados Unidos en 1898. En cualquier caso las influencias recíprocas en la mayor parte del entramado institucional son un hecho del constitucionalismo de la primera mitad del siglo XIX, en tanto que la proyección del texto de Cádiz sobre las elites burguesas que inspiran en ultramar el proceso de secesión y revuelta, también son acompañadas por la participación de muchos de los dirigentes indianos en los debates de las Cortes constituyentes, que trabajan en la España ocupada a partir de 1810.

Sería una tarea ardua y más propia de los historiadores generales o del derecho, el ponderar o calibrar cuánta influencia recibe un texto constitucional, o una concreta institución o derecho, de ordenamientos precedentes propios o comparados; o más bien, de cualquier estructura jurídica anterior. Lo único que al menos cabe concluir desde disciplinas distintas, como la nuestra, es que en todo el proceso de conformación de estas nuevas estructuras políticas y administrativas, las primeras plazas del conjunto de influencias, se la llevarían la experiencia de Norteamérica, a partir de 1776, y la Revolución Francesa desde la década siguiente. Mucho se ha tratado de todo ello también en España desde Melchor Fernández Almagro (Orígenes del régimen constitucional en España, Labor, Madrid, 1928).

Descendiendo al ámbito de la primera generación de derechos, nuestra Constitución de 1812, sigue siendo centro de atención del derecho político y constitucional español, así como de la historia moderna. Es el texto liberal que inspira la mayor parte de avances observados en el constitucionalismo español previo a la llegada de influencias socialistas, y su repercusión es clara en buen número de ordenamientos de las nuevas repúblicas independientes de América Latina, y en los textos más avanzados del siglo XIX español (1837 o 1869, entre otros).

Las conmemoraciones, como esta del bicentenario de la elaboración y promulgación del texto constitucional de 1812, tienen sentido en tanto queda de lo recordado algo que mantener. Las celebraciones de cumpleaños de los muertos nunca han tenido sentido en ninguna cultura a no ser que el finado hubiera dejado una huella indeleble en sus descendientes (o subsidiariamente una considerable fortuna). Pero de aquella guerra y sus circunstancias políticas, institucionales y jurídicas; se ha extraído por el constitucionalismo histórico español un sustrato ideológico, que se proyecta con marcada claridad en el derecho posterior ${ }^{16}$.

16 E. Belda Pérez-Pedrero, Prólogo al libro de J. López De Lerma Galán, Prensa y poder político en las Cortes de Cádiz. Cortes Generales, Madrid, Congreso de los Diputados, 2011, pp. 15 a 19. 


\title{
11. LOS PRECEPTOS QUE HUBIERAN SIDO CLAVES EN LA TRANSFORMACIÓN DE ESPAÑA
}

Es descartable en el derecho, el mundo de la ficción, y casi prohibido en una publicación científica, pero de haber disfrutado un período de vigencia prolongado, la Constitución de 1812 podría haber iniciado una senda de aplicación efectiva avanzando en el camino de la normatividad real, camino de situarse en la práctica en una auténtica ley de leyes. No fue así y el derecho comparado ofrece numerosos ejemplos de la ralentización de ese proceso. Por ello, los siguientes preceptos son más, de nuevo y como ocurre en la totalidad de la temática aportada a su consideración en estas jornadas, el comienzo de la singladura del constitucionalismo moderno. Es decir, el inicio de la sumisión del poder a un derecho creado por el pueblo (en realidad, por su representación ocasional, pero no es poco).

\section{a) Concepción decimonónica de soberanía ligada a la nación}

\author{
“TÍTULO I \\ De la Nación española y de los españoles \\ CAPÍTULO I \\ De la Nación española
}

Art. 1. La Nación española es la reunión de todos los españoles de ambos hemisferios.

Art. 2. La Nación española es libre e independiente, y no es ni puede ser patrimonio de ninguna familia ni persona.

Art. 3. La soberanía reside esencialmente en la Nación, y por lo mismo pertenece a ésta exclusivamente el derecho de establecer sus leyes fundamentales".

\section{b) Inicio del sometimiento del poder tradicional}

\author{
"CAPÍTULO III \\ Del Gobierno
}

Art. 14. El Gobierno de la Nación española es una Monarquía moderada hereditaria.

Art. 15. La potestad de hacer las leyes reside en las Cortes con el Rey. 


\title{
$(\ldots)$
}

Art. 17. La potestad de aplicar las leyes en las causes civiles y criminales reside en los tribunales establecidos por la ley. ”.

\section{c) Fin del poder absoluto regio}

\author{
"TÍTULO IV \\ Del Rey \\ CAPÍTULO I \\ De la inviolabilidad del Rey, y de su autoridad
}

\section{( ...)}

Art. 172. Las restricciones de la autoridad del Rey son las siguientes: $1^{a}$. No puede el Rey impedir bajo ningún pretexto la celebración de las Cortes en las épocas y casos señalados por la Constitución, ni suspenderlas ni disolverlas, ni en manera alguna embarazar sus sesiones y deliberaciones. Los que le aconsejasen o auxiliasen en cualquier tentativa para estos actos, son declarados traidores, y serán perseguidos como tales.

$2^{a}$. No puede el Rey ausentarse del reino sin consentimiento de las Cortes; y si lo hiciere se entiende que ha abdicado de la corona.

$3^{a}$. No puede el Rey enajenar, ceder, renunciar o en cualquier manera traspasar a otro la autoridad real, ni alguna de sus prerrogativas.

Si por cualquiera causa quisiera abdicar el trono en el inmediato sucesor, no lo podrá hacer sin el consentimiento de las Cortes.

$4^{a}$. No puede el Rey enajenar, ceder o permutar provincia, ciudad, villa o lugar, ni parte alguna, por pequeña que sea, del territorio español.

$5^{a}$. No puede el Rey hacer alianza ofensiva, ni tratado especial de comercio con ninguna potencia extranjera sin el consentimiento de las Cortes.

6 . No puede tampoco obligarse por ningún tratado a dar subsidios a ninguna potencia extranjera sin el consentimiento de las Cortes.

$7^{\mathrm{a}}$. No puede el Rey ceder ni enajenar los bienes nacionales sin consentimiento de las Cortes.

$8^{a}$. No puede el Rey imponer por sí directa ni indirectamente, ni hacer pedidos bajo cualquier nombre o para cualquier objeto que sea, sino que siempre los han de decretar las Cortes.

$9^{a}$. No puede el Rey conceder privilegio exclusivo a persona ni corporación alguna. 
$10^{a}$. No puede el Rey tomar la propiedad de ningún particular ni corporación, ni turbarle en la posesión, uso y aprovechamiento de ella; y si en algún caso fuere necesario para un objeto de conocida utilidad común tomar la propiedad de un particular, no lo podrá hacer, sin que al mismo tiempo sea indemnizado, y se le dé el buen cambio a bien vista de hombres buenos.

$11^{a}$. No puede el Rey privar a ningún individuo de su libertad, ni imponerle por sí pena alguna. El secretario del Despacho que firme la orden, y el juez que la ejecute, serán responsables a la Nación, y castigados como reos de atentado contra la libertad individual.

Sólo en el caso de que el bien y seguridad del Estado exijan el arresto de alguna persona, podrá el Rey expedir órdenes al efecto; pero con la condición de que dentro de cuarenta y ocho horas deberá hacerla entregar a disposición del tribunal o juez competente.

$12^{a}$. El Rey antes de contraer matrimonio dará parte a las Cortes para obtener su consentimiento; y si no lo hiciere entiéndase que abdica la corona".

\title{
d) Primeros pasos de la representación (sufragio restringido)
}

\author{
“TÍTULO III \\ De las Cortes \\ CAPÍTULO I \\ Del modo de formarse las Cortes
}

Art. 27. Las Cortes son la reunión de todos los diputados que representan la Nación, nombrados por los ciudadanos en la forma que se dirá”.

\section{e) Dotación competencial reglada a los representantes de la soberanía}

"CÁPITULO VII

De las facultades de las Cortes

Art. 131. Las facultades de las Cortes son:

$1^{\mathrm{a}}$. Proponer y decretar las leyes, e interpretarlas y derogarlas en caso necesario.

$2^{a}$. Recibir el juramento al Rey, al Príncipe de Asturias y a la Regencia, como se previene en sus lugares.

$3^{a}$. Resolver cualquier duda, de hecho o de derecho, que ocurra en orden a la sucesión a la corona. 
$4^{a}$. Elegir Regencia o Regente del reino cuando lo previene la Constitución, y señalar las limitaciones con que la Regencia o el Regente han de ejercer la autoridad real.

$5^{\text {a }}$. Hacer el reconocimiento público del Príncipe de Asturias

6a. Nombrar tutor al Rey menor, cuando lo previene la Constitución,

$7^{\text {a }}$. Aprobar antes de su ratificación los tratados de alianza ofensiva, los de subsidios, y los especiales de comercio.

$8^{\text {a }}$. Conceder o negar la admisión de tropas extranjeras en el reino.

$9^{a}$. Decretar la creación y supresión de plazas en los tribunales que establece la Constitución e igualmente la creación y supresión de los oficios públicos.

$10^{a}$. Fijar todos los años a propuesta del Rey las fuerzas de tierra y de mar, determinando las que se hayan de tener en pie en tiempo de paz, y su aumento en tiempo de guerra.

$11^{a}$. Dar ordenanzas al ejército, armada y milicia nacional en todos los ramos que los constituyen.

$12^{a}$. Fijar los gastos de la administración pública.

$13^{a}$. Establecer anualmente las contribuciones e impuestos.

$14^{a}$. Tomar caudales a préstamos en casos de necesidad sobre el crédito de la Nación.

$15^{\mathrm{a}}$. Aprobar el repartimiento de las contribuciones entre las provincias.

$16^{a}$. Examinar y aprobar las cuentas de la inversión de los caudales públicos.

$17^{\mathrm{a}}$. Establecer las aduanas y aranceles de derechos.

$18^{a}$. Disponer lo conveniente para la administración, conservación y enajenación de los bienes nacionales.

$19^{\mathrm{a}}$. Determinar el valor, peso, ley, tipo y denominación de las monedas. $20^{\mathrm{a}}$. Adoptar el sistema que se juzgue más cómodo y justo de pesos y medidas.

$21^{\mathrm{a}}$. Promover y fomentar toda especie de industria y remover los obstáculos que la entorpezcan.

$22^{a}$. Establecer el plan general de enseñanza pública en toda la Monarquía, y aprobar el que se forme para la educación del Príncipe de Asturias.

$23^{a}$. Aprobar los reglamentos generales para la Policía y sanidad del reino.

$24^{a}$. Proteger la libertad política de la imprenta.

$25^{\text {a }}$. Hacer efectiva la responsabilidad de los secretarios del Despacho y demás empleados públicos.

$26^{a}$. Por último pertenece a las Cortes dar o negar su consentimiento en todos aquellos casos y actos, para los que se previene en la Constitución ser necesario". 


\title{
f) Independencia judicial e inicio de las garantías
}

“TíTULO V

De los Tribunales y de la Administración de Justicia en lo Civil y Criminal

CAPÍTULO I

De los Tribunales

Art. 242. La potestad de aplicar las leyes en las causas civiles y criminales pertenece exclusivamente a los tribunales.

Art. 243. Ni las Cortes ni el Rey podrán ejercer en ningún caso las funciones judiciales, avocar causas pendientes, ni mandar abrir los juicios fenecidos".

\section{(...)}

Art. 247. Ningún español podrá ser juzgado en causas civiles ni criminales por ninguna comisión, sino por el tribunal competente determinado con anterioridad por la ley.

Art. 248. En los negocios comunes, civiles y criminales no habrá más que un solo fuero para toda clase de personas".

\section{g) Asunción al máximo nivel de los principios financieros}

“TÍTULO VII

De las contribuciones

CAPÍTULO ÚNICO

Art. 338. Las Cortes establecerán o confirmarán anualmente las contribuciones, sean directas o indirectas, generales, provinciales o municipales, subsistiendo las antiguas, hasta que se publique su derogación o la imposición de otras.

Art. 339. Las contribuciones se repartirán entre todos los españoles con proporción a sus facultades, sin excepción ni privilegio alguno.".

h) Tímida aparición de un régimen de derechos reglado

\author{
“TÍTULO I \\ CAPÍTULO IV \\ De los ciudadanos españoles
}


Art. 18. Son ciudadanos aquellos españoles que por ambas líneas traen su origen de los dominios españoles de ambos hemisferios y están avecindados en cualquier pueblo de los mismos dominios.

Art. 19. Es también ciudadano el extranjero que gozando ya de los derechos de español, obtuviere de las Cortes carta especial de ciudadano.

Art. 20. Para que el extranjero pueda obtener de las Cortes esta carta, deberá estar casado con española, y haber traído o fijado en las Españas alguna invención o industria apreciable, o adquirido bienes raíces por los que pague una contribución directa, o estableciéndose en el comercio con un capital propio y considerable a juicio de las mismas Cortes, o hecho servicios señalados en bien y defensa de la Nación.

Art. 21. Son, asimismo, ciudadanos los hijos legítimos de los extranjeros domiciliados en las Españas, que habiendo nacido en los dominios españoles, no hayan salido nunca fuera sin licencia del Gobierno, y teniendo veinte y un años cumplidos, se hayan avecindado en un pueblo de los mismos dominios, ejerciendo en él alguna profesión, oficio o industria útil.

Art. 22. A los españoles que por cualquier línea son habidos y reputados por originarios del África, les queda abierta la puerta de la virtud y del merecimiento para ser ciudadanos: en su consecuencia las Cortes concederán carta de ciudadano a los que hicieren servicios calificados a la Patria, o a los que se distingan por su talento, aplicación y conducta, con la condición de que sean hijos de legítimo matrimonio de padres ingenuos; de que estén casados con mujer ingenua, y avecindados en los dominios de las Españas, y de que ejerzan alguna profesión, oficio o industria útil con un capital propio.

Art. 23. Sólo los que sean ciudadanos podrán obtener empleos municipales, y elegir para ellos en los casos señalados por la ley.

Art. 24. La calidad de ciudadano español se pierde:

1. ${ }^{\circ}$ Por adquirir naturaleza en países extranjeros

2. ${ }^{\circ}$ Por admitir empleo de otro Gobierno.

3. ${ }^{\circ}$ Por sentencia en que se impongan penas aflictivas o infamantes, si no se obtiene rehabilitación.

4. ${ }^{\circ}$ Por haber residido cinco años consecutivos fuera del territorio español sin comisión o licencia del Gobierno. 
Art. 25. El ejercicio de los mismos derechos se suspende:

$1 .^{\circ}$ En virtud de interdicción judicial por incapacidad física o moral.

$2 .^{\circ}$ Por el estado de deudor quebrado, o de deudor a los caudales públicos.

3. ${ }^{\circ}$ Por el estado de sirviente doméstico.

4. ${ }^{\circ}$ Por no tener empleo, oficio o modo de vivir conocido.

$5 .^{\circ}$ Por hallarse procesado criminalmente.

$6 .^{\circ}$ Desde el año de mil ochocientos treinta deberán saber leer y escribir los que de nuevo entren en el ejercicio de los derechos de ciudadano.

Art. 26. Sólo por las causas señaladas en los dos artículos precedentes se pueden perder o suspender los derechos de ciudadano, y no por otras.

(...)

TÍTULO IX

De la instrucción pública

CAPÍTULO ÚNICO

Art. 366. En todos los pueblos de la Monarquía se establecerán escuelas de primeras letras, en las que se enseñará a los niños a leer, escribir y contar, y el catecismo de la religión católica, que comprenderá también una breve exposición de obligaciones civiles.

Art. 367. Asimismo se arreglará y creará el número competente de universidades y de otros establecimientos de instrucción, que se juzguen convenientes para la enseñanza de todas las ciencias, literatura y bellas artes.".

\section{ApÉNDICE BIBLIOGRÁFICO (SELECCIÓN)}

ARTOLA, Miguel, Estudio preliminar a La Constitución de 1812, Madrid, Iustel, 2008.

ASENSI SABATER, José, La época constitucional, Valencia, Tirant lo Blanch, 1998.

BARRIOS PINTADO, Feliciano, El Consejo de Estado de la Monarquía española (1521-1812), Madrid, Ed. Consejo de Estado, 1984.

CANO BUESO, Juan (ed.), Materiales para el estudio de la Constitución de 1812, Madrid, Tecnos, 1989.

CLAVERO, Bartolomé, Manual de historia constitucional de España, Madrid, Alianza Editorial, 1989.

COLOMER VIADEL, Antonio, Introducción al constitucionalismo iberoamericano, Madrid, ICE, 1990. 
DIAZ REVORIO, Francisco Javier (comp.), Textos Constitucionales Históricos. El constitucionalismo Europeo y Americano en sus documentos, Lima, Palestra, 2004.

DIAZ REVORIO, Francisco Javier y José Manuel VERA SANTOS, $\mathrm{La}$ Constitución de 1812 y su difusión en Iberoamérica, Valencia, Tirant lo Blanc, 2012.

FERNÁNDEZ ALMAGRO, Melchor, Orígenes del régimen constitucional en España, Madrid, Labor, 1928.

FERRANDO BADÍA, Juan, "La Constitución española de 1812 en los comienzos del -Risorgimiento-", en Cuadernos del Instituto Jurídico Español, núm. 10 (1959).

GARCÍA BELAUNDE, Domingo, "El constitucionalismo latinoamericano y sus influencias”, en Francisco Javier Díaz Revorio (comp.), Textos Constitucionales Históricos. El constitucionalismo Europeo y Americano en sus documentos, Lima, Palestra, 2004, pp. 37 a 50.

HERRERO GUTIÉRREZ, Rosario y otros (comp.), Las Cortes de Cádiz y la Constitución de 1812, Madrid, Cortes Generales, 1987.

JURETSCHKE, Hans, Los afrancesados en la Guerra de la Independencia, Madrid, Rialp, 1962.

LORENTE SARIÑENA, Marta y otros, Cádiz, 1812: la constitución jurisdiccional, Madrid, CEPC, 2007.

MARTÍNEZ CUADRADO, Miguel y otros, Dos constituciones liberales: 1812, 1978, Madrid, Unión Editorial, 1982.

MARTINEZ SOSPEDRA, Manuel, "La Constitución española de 1812", en Cátedra Fadrique Furrió Ceriol, núm. 11, 1978.

PORTILLO VALDÉS, José María, Revolución de nación: orígenes de la cultura constitucional en España, 1780-1812

CEPC-BOE, Madrid, 2000

SÁNCHEZ AGESTA, Luís, Introducción al Discurso Preliminar a la Constitución de 1812 a cargo de Agustín de Argüelles, Madrid, CEC, 1989.

SANTAMARÍA PASTOR, Juan Alfonso, Sobre la génesis del derecho administrativo español en el siglo XIX (1812-1845), Madrid, IUSTEL, 2006.

SEMPERE Y GUARINOS, Juan, Memoria primera sobre la Constitución gótico-española: Cádiz, 1812, en Biblioteca Saavedra y Fajardo de pensamiento político, estudio preliminar de Rafael Herrera Guillén, Madrid, Biblioteca Nueva, 2007.

VERA SANTOS, José Manuel, "La influencia del constitucionalismo francés en la fase de iniciación constitucional española (1808-1934)", en Revista de Derecho Político, Madrid, núm. 66 (2006), pp. 123 a 179.

VERA SANTOS, José Manuel, Las Constituciones de España, Madrid, Thomson-Civitas, 2008. 
